\title{
Paraganglioma de corpo carotídeo: relato de caso
}

\author{
Carotid body tumor: case report
}

\begin{abstract}
Ahmad Mohamad Ali Hamade', Ana Carolina Taveira Engler Raiz Coelho', André de Carvalho Sales Peres ${ }^{1}$, Daiana Barbosa Dias Melo', Ayder Anselmo Gomes Vivi
\end{abstract}

Hamade AMA, Coelho ACTER, Peres ACS, Melo DBD, Vivi AAG. Paraganglioma de corpo carotídeo: relato de caso / Carotid body tumor: case report. Rev Med (São Paulo). 2018 jan.-fev.;97(1):108-12.

\begin{abstract}
RESUMO: Os paragangliomas são tumores neuroendócrinos raros com origem em células especializadas derivadas da crista neural. No corpo carotídeo são raros e devem fazer parte do diagnóstico diferencial de tumores da região cervical. Este relato de caso apresenta uma paciente de 24 anos, gênero feminino, com queixa de abaulamento cervical à direita. Foi realizado o tratamento cirúrgico no Hospital Padre Albino. Nesse artigo os autores apresentam um caso de paraganglioma de corpo carotídeo, dando ênfase nos aspectos clínicos, diagnóstico e tratamento.
\end{abstract}

Descritores: Tumor do corpo carotídeo; Paraganglioma; Tumores neuroendócrinos; Crista neural.

\section{INTRODUÇÃO}

$\mathrm{O}$ s tumores de corpo carotídeo fazem parte de uma família de neoplasias neuroendócrinas as quais recebem o termo genérico Paraganglioma. Possuem caráter raro (2: 1 milhão/ano), crescimento lento, hipervascularizados e geralmente benignos (97\%), correspondendo a aproximadamente metade do total de paragangliomas e cerca de $0,6 \%$ dos tumores de cabeça e pescoço $\mathrm{O}^{1,2,3}$.
ABSTRACT: Paragangliomas are rare neuroendocrine tumors that originate in specialized cells derived from neural crest cells. Carotid body tumors are rare and they must always be part of the differential diagnosis of the tumors in the cervical region. This report presents the case of a 24-year-old, female, with a complaint of a right cervical node. Surgical treatment was performed at the Padre Albino Hospital. The authors present a case of a carotid body paraganglioma, its clinical aspects, diagnosis and treatment.

Keywords: Carotid body tumor; Paraganglioma; Neuroendocrine tumors; Neural crest.

*Trabalho apresentado no XXXII Congresso Brasileiro de Cirurgia, São Paulo, SP, 30 abr. 2017.

1. Faculdades Integradas Padre Albino, Catanduva, SP, BR. Acadêmicos de Medicina. Emails: ahmad.hamade.75@hotmail.com; ac.engler@hotmail.com; andresperes_asp@hotmail.com; dai.bmelo@gmail.com. ORCID: Hamade AMA: http://orcid.org/00000001-9834-6461; Coelho ACTER: http://orcid.org/0000-0002-6510-0075; Peres ACS: http://orcid.org/0000-0001-9477-8742; Melo DBD: http://orcid.org/0000-0003-1695-1030.

2. Faculdades Integradas Padre Albino, Catanduva, SP, BR. Professor titular do Departamento de Cirurgia do Curso de Medicina. ORCID: http://orcid.org/0000-0003-4633-288X

Endereço para correspondência: Daiana Barbosa Dias Melo. Rua dos Estudantes, $n^{\circ} 75$. Parque Iracema, Catanduva, SP, BR. 
respostas reflexas para corrigí-los, tanto vasomotoras como respiratórias ${ }^{2}$.

Essas lesões podem ser unilaterais ou bilaterais e de localização variável - posterior à artéria carótida comum ou entre as artérias carótidas interna e externa. Entretanto, a maioria se apresenta na forma unilateral e de caráter esporádico $(75 \%)$, com maior prevalência em casos familiares (10 a $25 \%$ ) na forma bilateral. A ressecção cirúrgica do tumor oferece uma taxa de controle do tumor de cerca de $60 \%-72 \%$ ou superior de acordo com a localização e pode estar associada com imediato dano cerebrovascular, relacionando-se principalmente com o comprometimento da artéria carótida pelo tumor. Porém, devido à evolução dos métodos diagnósticos, da técnica cirúrgica e do suporte pós-operatório foram obtidos melhores resultados do tratamento, com grande diminuição da morbimortalidade ${ }^{4,5}$.

Para o auxílio na escolha do tratamento, esses tumores são classificados de acordo com Shamblin et al. ${ }^{6}$, e divididos em três categorias de acordo com a extensão circunferencial e o grau de aderência: tipo 1 - tumor pequeno menor que $4 \mathrm{~cm}$ sem aderência aos vasos e facilmente ressecável sem causar danos às estruturas vizinhas; tipo 2 - tumor intermediário, maior que $4 \mathrm{~cm}$ e com pequena aderência aos vasos carotídeos cuja dissecção é mais difícil, sendo necessária, às vezes, a revascularização; tipo 3 - tumor grande que rodeia completamente as carótidas com infiltração nos vasos cuja dissecção se torna quase impraticável, sendo necessária a ressecção em bloco com bifurcação carotídea e realização de revascularização com veia safena ou prótese ${ }^{2,6}$.

\section{RELATO}

C.A.P. feminino, 24 anos, raça branca, comerciária. Queixa-se de um abaulamento cervical à direita que vem crescendo nos últimos 7 meses. Nega disfagia, dores de cabeça, crises de hipertensão arterial e taquicardia ou casos similares familiares.

Ao exame clínico observou-se massa indolor, palpável, de aproximadamente $5 \mathrm{~cm}$, parcialmente móvel, pulsátil à direita, próximo ao ângulo da mandíbula.

Foram realizados os seguintes exames: ultrassonografia Doppler, tomografia computadorizada e angiografia com reconstrução 3D. Os resultados revelaram formação ovalada heterogênea projetado à direita do pescoço em íntimo contato com as carótidas internas, externas e jugulares, medindo aproximadamente 5,0 $\mathrm{cm}$, sugestivo de paraganglioma e com afastamento das carótidas interna e externa conforme Figura 1. Não foi realizada biópsia, pois estava formalmente contra-indicada devido ao risco de hemorragia de difícil controle e esta não ser conclusiva, mesmo com PAAF.

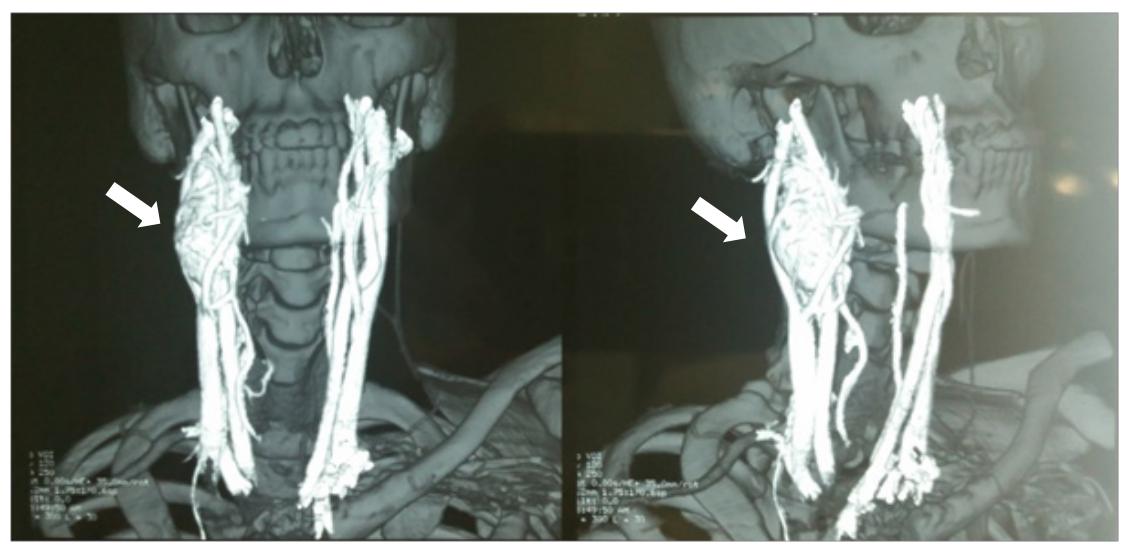

Figura 1 - Extensa formação tumorosa, hipervascularizada, acometendo a bifurcação da artéria carótida direita

Uma das possibilidades de tratamento é a cirúrgica e, levando-se em consideração a idade do paciente e o tumor em crescimento, essa é a escolha. A cirurgia foi feita com a paciente sob anestesia geral, em decúbito dorsal, com cabeça rodada entre 25 e 30 graus para o lado contralateral e ligeiramente estendida. Foi realizada uma incisão oblíqua seguindo a borda anterior do músculo esternocleidomastóideo se estendendo até o processo mastóideo. Após adequada exposição, o músculo digástrico e estilóideo foram seccionados e o nervo hipoglosso isolado. Foi realizado então isolamento do tumor e dissecção cautelosa.
A ligadura e rafia da carótida externa foi realizada com fio de prolene 4.0, gerando estreitamento da luz da artéria, posto que o tumor se dava na bifurcação das carótidas. Achamos melhor devido a idade da paciente e o fluxo contralateral ser bastante efetivo, não utilizarmos material sintético ou técnica outra que não a simples rafia mesmo que gerando certo estreitamento. Cabe ressaltar que já no intraoperatório o fluxo da carótida a jusante da rafia era bem efetivo.

Não ocorreram danos neurológicos após a cirurgia. Não foi realizada embolização prévia sendo que há controvérsias acerca da eficácia desse procedimento. 

benigno.

O exame histopatológico revelou paraganglioma

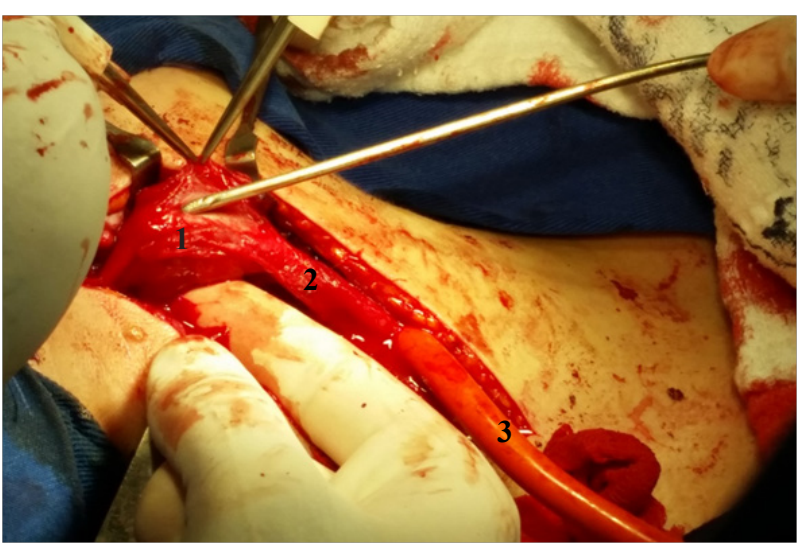

Figura 2 - Tumor exposto antes da ressecção cirúrgica. 1: tumor; 2: carótida comum; 3: dreno de borracha

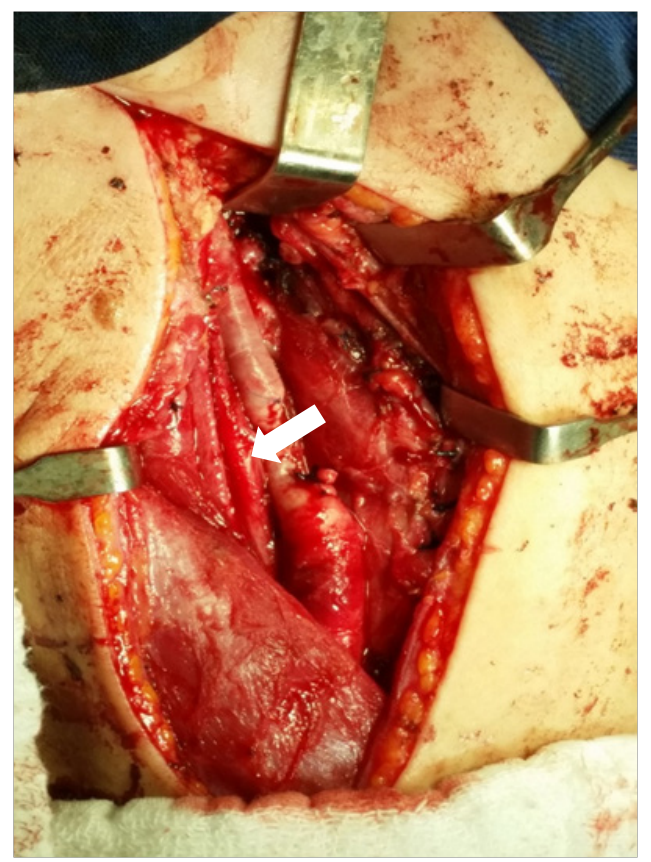

Figura 3 - Campo cirúrgico com o ato operatório finalizado na bifurcação da carótida. Artéria carótida externa precisou ser ligada

\section{DISCUSSÃO}

Paraganglioma é um termo genérico que engloba tumores de células neuroendócrinas, as quais podem estar na medula da adrenal ou nos gânglios difusos ${ }^{1}$. A maioria dos paragangliomas não é de origem genética, contudo 10 a $50 \%$ destes tumores são hereditários, se manifestando através de um gene autossômico dominante ${ }^{3,7}$. Estudos recentes descreveram uma mutação ao longo das linhas germinativas, o que pode explicar a etiologia, através da identificação de seis genes específicos (RET, VHL, NF1 e subunidades de SDH) . A forma hereditária está principalmente correlacionada com mutações no gene
SDHD $^{5,7}$.Assim, estudos imunohistoquímicos podem auxiliar no diagnósticos desses casos.

A história clínica do paciente com paraganglioma de corpo carotídeo é diversa, sendo as principais manifestações uma massa indolor de crescimento lento com movimento horizontal maior que o vertical ${ }^{5}$. Ademais, em certos casos pode cursar com rouquidão, sensação de corpo estranho na faringe, dificuldade para deglutir e problemas na movimentação da língua ${ }^{1}$. Essas manifestações podem nos fornecer diagnósticos diferenciais para linfoadenopatias, tumor de glândulas salivares, schwanomas, aneurisma de artéria carótida e cisto braquial ${ }^{5}$.

Os exames complementares são essenciais para a confirmação do diagnóstico, sendo a CAAF (citologia aspirativa com agulha fina) pouco recomendada pelo risco de hemorragia e resultados pouco conclusivos, pois o comportamento morfológico deste tumor neuroendócrino é altamente variável. A melhor escolha é a ultrassonografia com Doppler que nos fornecerá uma lesão hipoecoica altamente vascularizada e sólida na região da bifurcação da carótida ${ }^{2,5}$. São exames importantes para a programação cirúrgica a angiografia, a tomografia computadorizada axial, a ressonância magnética e as imagens com isótopo radioativo $^{2}$.

O exame da angiografia convencional irá nos auxiliar na classificação destes tumores segundo os critérios de tamanho, relação com bifurcação de carótida e estruturas adjacentes propostos por Shamblin et al. ${ }^{6}$.

Esta classificação auxilia no tratamento, geralmente optando-se pela cirurgia, pois a remoção completa de um tumor de corpo carotídeo oferece uma excelente probabilidade de controle da doença a longo prazo, tendo em vista a possibilidade de malignização, invasão peritumoral e metastização deste. A técnica mais utilizada é a dissecção subadventicial do tumor (Gordon-Taylor). A ressecção em bloco é utilizada apenas nos casos em que é inviável separar o tumor da artéria, e deve ser seguida de interposição de um enxerto para a carótida interna. Há indicação de dissecção para tumores que possuem menos de $6 \mathrm{~cm}$ e extensão circunferencial incompleta, com ângulo da bifurcação menor que $90^{\circ}$ e os que devem ser abordados por ressecção são os maiores de 6 cm e extensão circunferencial completa, com ângulo da bifurcação maior que $90^{\circ}$. Considera-se inoperável quando o tumor envolve toda a carótida interna extracraniana, tornando impossível a anastomose distal com enxerto ou prótese $\mathrm{e}^{4,8}$.

Quanto ao papel da embolização pré-operatória, destaca-se seu uso no caso de grandes tumores, em que ela reduz a perda sanguínea e o tamanho da massa tumoral e melhora os resultados cirúrgicos, porém não se pode descartar o risco de embolia cerebral ${ }^{7}$.

A cirurgia foi executada exclusivamente pelo cirurgião de cabeça e pescoço. Foi realizada incisão oblíqua decorrente do tamanho do tumor e sua extremidade distal (cefálica) ser muito abaixo e acima do ângulo da mandíbula, 
tornando-se difícil e inapropriado, devido à falta de segurança, lidarmos com esta região em incisão transversa, assim avaliado pela equipe cirúrgica. Para a segurança da paciente e não comprometimento do procedimento a equipe multidisciplinar (equipe de cirurgia vascular) estavam em sala de prontidão caso necessário.

O tratamento cirúrgico fornece possíveis dificuldades diretamente dependentes da sua relação do tumor com a carótida e com o seu tamanho ${ }^{4}$. Dentre as dificuldades da presente cirurgia, destacou-se o grande volume do tumor como a maior dificuldade e seu grande envolvimento do glomus carotídeo. Para minimizarmos o sangramento e tornar o ato operatório mais claro e exequível clampeamos a artéria carótida comum com fita cardíaca através de um dreno de borracha macio e tracionamos. Os vasos (carótida interna e externa) a jusante da lesão não foram clampeados, o que nos permitia evidenciar pequenos pontos que deveriam ser ligados com ligadura simples de fio fino de algodão. Preservar a carótida comum e interna era desde o início nosso objetivo não só para encurtar o ato operatório como também minimizar o uso de próteses. Os vasos da paciente em questão, pela idade da mesma eram bastante íntegros e permitiam o manuseio e suturas.

Tendo-se em vista que as taxas de complicações gerais variam entre 32 e $44 \%$, e as taxas de mortalidade variam entre 8 e $20 \%$, a cirurgia deve ser realizada cuidadosamente para evitar ressecção na carótida e possível hemorragias graves ${ }^{2,8}$. A maior causa de morbidade é a lesão de pares cranianos, em sua maioria os nervos hipoglosso e vago, mas também pode-se acometer o nervo laríngeo superior que ocasionam paralisias muitas vezes definitivas. Complicações mais graves, como infarto cerebral e hemorragia de difícil controle, são mais raras. A linfadenectomia deve ser realizada em caso de metástase $\mathrm{e}^{3,8}$.

$\mathrm{O}$ uso de shunt intra-operatório pode permitir uma abordagem mais segura para a ressecção de artéria carótida interna por manter o fluxo cranial durante o procedimento, mas seu uso não é isento de complicações, associando-se a uma morbidade de $6,4 \%$ e mortalidade de $6 \%{ }^{4}$. Deve-se, portanto, avaliar o real benefício do ato operatório (idade, condições clínicas e grau de comprometimento imposto pelo paraganglioma).
O uso de teste de oclusão para avaliar a permeabilidade do polígono de Willis é apontado como uma importante forma de avaliar a tolerância do paciente à oclusão da artéria carótida interna, mas este procedimento também tem suas limitações ${ }^{4}$. Deste modo, não foi possível realizar o teste de oclusão nem tampouco arteriografia. A angiotomografia mostrava com bastante nitidez a vascularização da base do crânio (polígono de Willis) e nítida intercomunicação entre os hemisférios com patência vascular bastante evidente.

A realização da ligadura da carótida externa na presente cirurgia é controversa. A principal crítica à técnica é que ela não impede o fluxo retrógrado, de tal forma que o sangramento resultante da manipulação do tumor não será seriamente afetado. Entretanto, tal manobra é defendida por permitir a dissecção da face medial e posterior do bulbo carotídeo, bem como uma identificação mais fácil do nervo vago $^{4}$. As reconstruções devem ser sempre nosso objetivo, mesmo que a arteriografia mostre inequivocamente patência do polígono de Willis. Caso a lesão seja muito alta nas proximidades do forame lacerum a rafia se torna impraticável, não restando-nos opção outra que não sua ligadura.

Há outras opções terapêuticas, entre elas o tratamento conservador e a radioterapia. O tratamento conservador deve ser indicado a pacientes que não são adequados para cirurgia, como os clinicamente instáveis, pacientes extremamente idosos ou com a certeza de ocorrência de acidente vascular encefálico ou ainda se certamente haverá lesão de nervos cranianos que ainda não se instalaram. A radioterapia poderia ser usada, mas isso não é recomendado pela maioria das instituições ${ }^{7}$. Ela pode ser utilizada para tumores inacessíveis, parcialmente ressecados, metastáticos, em casos de recorrência local e nos pacientes em que a cirurgia tem altos índices de morbidade. Porém, é necessário lembrar que efeitos colaterais podem ocorrer, como necrose da mandíbula, cérebro e partes moles ${ }^{8}$.

Assim, após a realização do tratamento adequado, as taxas de controle dos paragangliomas a longo prazo são de $96 \%$.

Participação dos autores no artigo: Hamade AMA, Coelho ACTER, Peres ACS, Melo DBD - Autores escreveram o artigo com supervisão do docente Vivi AAG o qual realizou a cirurgia.

\section{REFERÊNCIAS}

1 Hevia Costa ME. Actualización del manejo diagnóstico y terapêutico del paraganglioma. Rev Cubana Endocrinol. 2014;25(3):149-62. Disponible en: http:// scielo.sld.cu/scielo.php?script $=$ sci_arttext\&pid $=$ S1561 29532014000300003\&lng=es.

2 Yanez RM, Loyola FB, Cornejo JF. Tumor de cuerpo carotídeo. Rev Chil Cir. 2011;63(5):513-8. doi: http://dx.doi. org/10.4067/S0718-40262011000500013.
3 Oliveira M, Caratão F, Costa P. Paraganglioma cervical: um caso clínico. Rev Port Oncol. 2013;3:43-6. Disponível em: https://www.sponcologia.pt/fotos/editor2/revistas/rpo3.pdf.

4 Kohler HF, Carvalho AL, Nishinari K, Kowalski LP. Reconstrução da artéria carótida interna após ressecção de tumor de corpo carotídeo: relato de seis casos e análise das técnicas disponíveis. Rev Bras Cir Cabeça Pescoço. 2010;39(3):210-3. Disponível em: http://www.sbccp.org. 
br/wp-content/uploads/2014/11/REVISTA-SBCCP-39-3artigo-12.pdf

5 Peric B, Marinzec ZP, Skrbinc B, Music M, Zagar I, Hocevar M. A patient with a painless neck tumour revealed as a carotid paraganglioma: a case report. World J Surg Oncol. 2014;12:267. doi: 10.1186/1477-7819-12-267.

6 Shamblin WR, Remine WH, Sheps SG, Harrison EG. Carotid body tumor (chemodectoma). Clinicopathologic analysis of ninety cases. Am J Surg. 1971;122(6):732-9. doi: http://dx.doi. org/10.1016/0002-9610(71)90436-3.
7 Casarim ALM, Tincani AJ, Del Negro A, Aguiar CG, Fanni RV, Martins AS. Carotid body tumor: retrospective analysis on 22 patients. Sao Paulo Med. J. 2014;132(3):133-9. doi: http://dx.doi.org/10.1590/1516-3180.2014.1323452.

8 Mesquita Junior N, Silva RS, Ribeiro JHA, Batista LC, Bringhentti, SEM, Souza, BBB, Cabral LCM. Tumor de corpo carotídeo (paraganglioma): relato de dois casos submetidos a tratamento cirúrgico. J Vasc Bras. 2016;15(2):158-64. doi: http://dx.doi.org/10.1590/1677-5449.007315.

Recebido em: 27.08.17

Aceito em: 05.01.18 